\title{
トマトの養液栽培における水分ストレスに応じた 給液制御システムの開発(1)
}

一茎径変化による水分ストレスの非破壊評価——

\author{
大 石 直 記 $^{1}$ \\ 静岡県農業試験場 \\ 1 現在：静岡県農林水産部
}

\author{
Development of Irrigation Control System in Response to Plant Water Stress \\ in Tomato Hydroponics (1)
}

- Non-Destructive Evaluation of Plant Water Stress by the Change of Stem Diameter-

\author{
Naoki OISHI ${ }^{1}$ \\ Shizuoka Agricultural Experiment Station, Iwata-gun, Shizuoka 438-0803, Japan \\ ${ }^{1}$ Present address : Department of Agriculture, Forestry and Fisheries, Shizuoka Prefectural Office, \\ Shizuoka 420-8601, Japan
}

(Received July 18, 2001)

\begin{abstract}
In order to develop an irrigation control system for applying optimum water stress to produce high-Brix tomato fruits with restricted root-zone hydroponics, a non-destructive evaluation method of water stress by measuring stem diameter (SD) was investigated. SD was continuously measured by using a laser sensor at internode between the 2 nd and the 3rd leaves of tomato plant during the growing period. Relative stem diameter (RSD) was used as an index of a water stress, which is calculated from a percentage of SD toward maximum stem diameter (MSD). When RSD is $100 \%$, there is no water stress. And if the RSD is smaller than $100 \%$, an intensity of water stress is bigger. RSD indicated a diurnal change which decreased to less than $100 \%$ after the sunrise and recovered to $100 \%$ from the evening to midnight. With a substrate drying, the relationship between RSD and leaf photosynthetic rate (Pr) was expressed as linear regression lines with high coefficient of correlation. The positive correlation between RSD in one plant grown in cultivation bed and relative water content (RWC) of leaves in other plants was investigated, except for the harvesting time of the double-truss cultivation. These results indicate that RSD is useful for an evaluation of water stress as an index for irrigation control in tomato cultivation, while a time constraint should be concerned in evaluating water stress by RSD measured at same stem position.
\end{abstract}

Keywords : irrigation control system, laser sensor, photosynthesis, stem diameter

2001 年 7 月 18 日受付

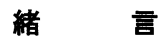

近年，トマトは糖度の高い果実が好まれ，その需要
が拡大している。トマトの果実糖度は，水分ストレス を付与することによって上昇することが知られており (Tochigi and Kawasato, 1989 ; Mitchell et al., 1991), 灌水制限による高糖度トマト生産が土耕栽培を中心に

Corresponding author: Naoki Oishi, fax : +81-54-221-2839, e-mail : naoki1_ohishi@ @q.pref.shizuoka.jp 
行われている (Muramatu, 1992)。しかし，栽培期間を 通じて適度な水分ストレスを付与するためには, 高度 な灌水管理技術が不可欠である。すなわち, 灌水量が 過多となり水分ストレスの付与が充分でないと糖度の 上昇程度は小さく, 逆に灌水量が過少となり一時的で はあっても強い水分ストレスが付与されると, 葉身の 萎调・枯死, 着果不良, 一果重の減少等が発生し, 著 しい減収を招く可能性がある.

著者らは, 少量のロックウール細粒綿を培地として 用いる根域制限式養液栽培システムによって, 高糖度 トマト生産が可能であることを明らかにした (Oishi et al., 1996).この栽培システムの培地量は 1 株当たり約 $200 \mathrm{ml}$ と少なく, 短時間で培地内の水分量を隇少させ ることができるので, 確実な水分ストレスの付与が可 能である.しかし, 適度な水分ストレスを付与するた めには生育や気象環境に応じて自動的に給夜を制御で きるシステムの開発があわせて必要である.

作物の水分ストレスは, 蒸散量が一時的に吸水量を 上まわることによって生じるが，このバランスを決定 する蒸散および吸水速度は気象環境や培地内水分等の 影響を受けて時々刻々変動する。 そこで, 養液栽培で は水分ストレスを適切に制御するため, 作物の蒸散お よび吸水に関わる積算日射量や培地内水分量を指標と する自動給液制御システムが用いられている（Tanaka, 1987). しかし, 前者は蒸散量を精度良く推定す るための指標としては充分でなく (Kamota et al., 1972 ; Nakamura et al., 1988 ; Sato 1989), 後者は水分 センサの適用条件 (培地種類, 培地量等) に制約があ る (Tanaka and Yasui, 1992)。したがって,これらの 制御方式のどちらも, 著者らの開発した根域制限式養 液栽培システムにそのまま適用することは困難であ る.

近年, 作物の生体計測によって体内水分状態を非破 壊的に評価する方法が検討されている (Iwao and Takano, 1988a ; Nakahara and Inoue, 1997).この中 でも茎径変化は, 作物体の水分ポテンシャルを表す指 標として有効であることが報告されている（Nagano and Shimaji, 1976; Iwao and Takano, 1988b ; Imai et al., 1990, 1994). さらに, Yamada and Kajioka (1991) と Sato and Hasegawa（1995）は, レーザ式変位セン サを用いた非接触式の茎径測定法を検討し，本方法に よって長期間にわたる茎径の簡易測定が可能であるこ とを明らかにしている。したがって，レーザ式変位セ ンサによる茎径測定を通じた水分ストレスの連続評価
方法が確立できれば，水分ストレスに応じた自動給夜 制御に応用することが可能と考えられる (Sato and Hasegawa, 1995). しかし, 現在のところ茎径変化から 水分ストレスを長期間にわたって連続的に評価できる 方法は確立していないため, 茎径変化を指標とした給 液制御は実用化されていない。

本研究では, 養液栽培による高糖度トマト生産を目 的として, 適度な水分ストレスが付与できる給液制御 技術を開発するため, レーザ式変位センサによってト マトの茎径変化を非破壊連続測定し, 水分ストレスの 評価法の検討を行った.

\section{材料および方法}

\section{1. レーザ式変位センサによる茎径測定法}

茎径の測定は, レーザ式変位センサ (LX2-02,（株) キーエンス製）を用いて, Sato and Hasegawa（1995） の方法を用いて行った (Fig. 1)。このセンサは赤外線 レーザの投光器と受光器から構成され, 両器の間に物 体があるとレーザ光が遮られ, その遮光量から物体の 外径を測定できる(検出幅: $10 \mathrm{~mm}$, 分解能: $10 \mu \mathrm{m}$ ). センサの投光器及び受光器を $30 \mathrm{~mm}$ 間隔で取り付け たアルミ製固定器具にトマト茎を密着させた後, 茎の 測定部位の上下を固定器具にクリップで固定し, 直径 $(\mathrm{SD}: \mathrm{mm})$ を連続測定した。 なお, 本センサによって 得られたすべてのデー夕は, 各センサごとに求めた出 力值と気温との関係式によって温度補正して用いた。

\section{2. 水分ストレス指標の算出法}

水分ストレスを与えながら生育させた茎径肥大期の

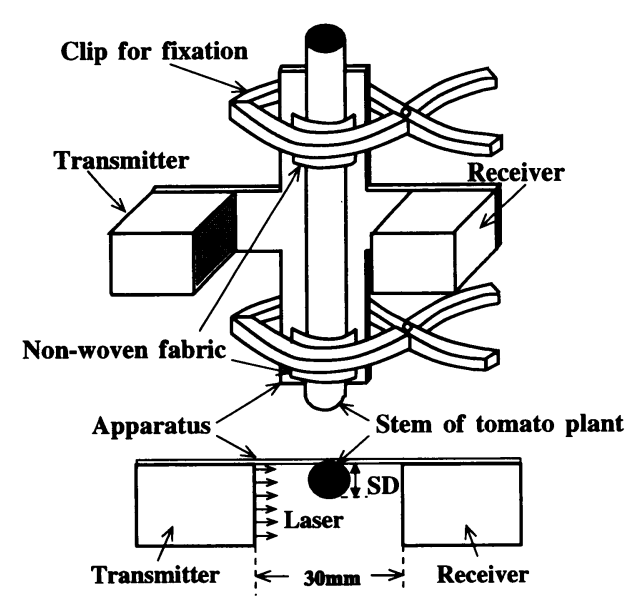

Fig. 1 Measurement method of stem diameter using laser sensor.

生物環境調節 (Environ. Control in Biol.) 

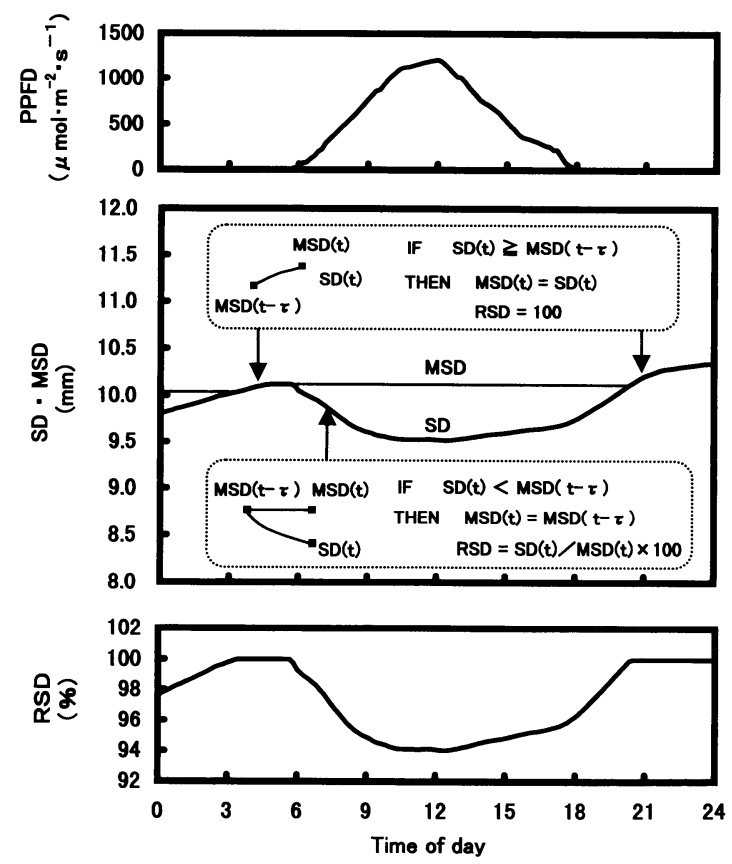

Fig. 2 Typical diurnal time courses of stem diameter (SD), photosynthetically photon flux density (PPFD), and calculation methods of maximum and relative stem diameter (MSD, RSD).

トマト株における, 晴天日の典型的な SD の日変化パ ターンを Fig. 2 に示した. その特徵は以下のとおりで ある.SD は, 深夜から早朝にかけて増加した後, 日の 出以降は PPFD の増加にともなって減少した。 また, SD は PPFD が最も大きくなる正午前後にその日の最 少值を示した後, 増加に転じ, 深夜にその日の最大値 を示した.ここで, 深夜から早朝の時間帯における SD の増加は, 蒸散の減少にともなう体内水分の増加と茎 の肥大生長によって生じ, 日の出以降の時間帯におけ るSD の減少は, 蒸散の増加にともなう体内水分の減 少および肥大生長の停止によって生じると推察される (Iwao and Takano, 1988b ; Imai et al., 1990). そこで, この考え方に基づき SD 変化から水分ストレスを連続 的に評価する指標として，以下に示した相対茎径 (RSD : \%) を求めた（Fig. 2).

$$
\begin{aligned}
& \mathrm{SD}(\mathrm{t}) \geqq \mathrm{MSD}(\mathrm{t}-\tau) \text { の場合 } \\
& \mathrm{MSD}(\mathrm{t})=\mathrm{SD}(\mathrm{t}) \\
& \operatorname{RSD}(\%)=100 \\
& \mathrm{SD}(\mathrm{t})<\mathrm{MSD}(\mathrm{t}-\tau) \text { の場合 } \\
& \mathrm{MSD}(\mathrm{t})=\mathrm{MSD}(\mathrm{t}-\tau) \\
& \operatorname{RSD}(\%)=\mathrm{SD}(\mathrm{t}) / \mathrm{MSD}(\mathrm{t}) \times 100
\end{aligned}
$$

$\mathrm{SD}(\mathrm{t})$ ：時刻 $\mathrm{t}$ における茎径 $(\mathrm{mm}) . \operatorname{MSD}(\mathrm{t}-\tau)$, $\mathrm{MSD}(\mathrm{t}):$ 時刻 $\mathrm{t}-\tau, \mathrm{t}$ までに記録された最大茎径 $(\mathrm{mm})$.

すなわち，ある時刻 $\mathrm{t} に$ 測定された $\mathrm{SD}(\mathrm{t})$ が，それ 以前の測定時刻 $\mathrm{t}$ 一までに記録された最大茎径 $(\operatorname{MSD}(\mathrm{t}-\tau))$ より大きいか等しい場合には, $\operatorname{MSD}(\mathrm{t})$ に SD $(\mathrm{t})$ を代入し, この時の RSD は $100 \%$ とする。いっ ぼう, $\mathrm{SD}(\mathrm{t})$ が $\mathrm{MSD}(\mathrm{t}-\tau)$ より小さい場合には, MSD (t) に $\mathrm{MSD}(\mathrm{t}-\tau)$ を代入し, この時の $\mathrm{RSD}$ は SD $(\mathrm{t})$ の $\mathrm{MSD}(\mathrm{t})$ に対する百分率で表すものとする.すなわ ち, 茎の肥大生長によって SD および MSD が増加傾 向を示す場合の RSD は 100\%として, 水分ストレスは ないとみなし, SD が MSD より小さい場合の RSD は 100\%以下の值をとり，その值が小さいほど水分ストレ スは大きいことを表す。

\section{3. 培地内水分の滅少にともなう相対茎径の推移と 葉身の光合成速度との関係}

トマト品種 ‘ハウス桃太郎”を用い, 1995 年 10 月 15 日にロックウール細粒綿を充填した 72 穴セルトレイ に播種した。10月 25 日に縦, 横 $100 \mathrm{~mm}$, 高さ $50 \mathrm{~mm}$ のロックウールキューブへ移植し, 静岡県農業試験場 内プラスチックハウス内で, 大塚ハウス $\mathrm{A}$ 処方 0.8 単 位の培養液（EC $2.0 \mathrm{dS} \cdot \mathrm{m}^{-1}$ ) を与えながら育苗した。 11 月 30 日に 6 葉期の健全な 2 株を用い, 上記培養液 処方の濃度を変えた EC 2.0 区 $\left(\mathrm{EC} 2.0 \mathrm{dS} \cdot \mathrm{m}^{-1}\right)$ 及び EC 6.0 区 $\left(\mathrm{EC} 6.0 \mathrm{dS} \cdot \mathrm{m}^{-1}\right)$ を設け，それぞれの培養 液でロックウールキューブを飽水状態にした後， 2 節 と 3 節の節間にレーザ式変位センサを設置した，翌日 の 12 月 1 日からの 4 日間にわたり,特に断らない限り 給液を停止し, SD を 30 分間隔で測定して RSD を算 出した.

茎径測定個体の第 3 葉小葉におけるみかけの光合成 速度 (Pr) は, 携帯型光合成蒸散測定装置 (SPB-H3, (株)島津製作所製）を用いて，毎日 7〜16 時に測定し た.

\section{4. 栽培条件における相対茎径と葉身の相対含水量 との関係}

1994 年 8 月 16 日に, トマト品種 “桃太郎” の 4 葉期 の苗を, 静岡県農業試験場内プラスチックハウス内に 設置した根域制限式養液栽培システム(方式：循環式, 栽培ベッド：長さ $8 \mathrm{~m}$, 培地：ロックウール細粒綿, 培 地量 : $200 \mathrm{ml} \cdot$ plant $^{-1}$ ) へ定植した。栽植条件は条間 $1.5 \mathrm{~m}$, 株間 $100 \mathrm{~mm}$ の 1 条振り分け誘引とし, 2 段花 房上の 3 葉を残して摘心した. 培養液は大塚八ウス $\mathrm{A}$ 
処方の $\mathrm{EC}$ 濃度 $2.0 \sim 3.0 \mathrm{dS} \cdot \mathrm{m}^{-1}$ で, 給液はしおれ程度 や天候に応じて, 1 回 $40 \mathrm{ml} \cdot$ plant $^{-1}$ として, 日中 1 17 回行った. 8 月 28 日の 8 葉期に, 栽培ベッド中央部の 1 株の第 2 節と第 3 節の節間にレーザ式変位センサを 取り付け, 10 分間隔で茎径データをコンピュータ (G200V，（株)東芝製)に取り込み，RSD を算出した。

葉身の相対含水量 (RWC) の測定は, 9 月 8 日及び 10 日の 1 段花房開花期 (11 葉期, 以下, 9 月測定), 10 月 4 日および 6 日の 2 段花房開花終期 (15 葉期, 以下, 10 月測定)，11月 7 日及び 8 日の 1 段花房収穫期（以 下，11 月測定）に各時期の最大展開葉位の小葉（9 月 測定 : 第 7 葉, 10 月測定 : 第 10 葉, 11 月測定: 第 13 葉）について行った。具体的な RWC の測定手順は以 下のとおりであった.各測定日の 6 時から 18 時までの 1 時間おきに, 栽培ベッド (南北畦) の南側, 中央, 北 側の 3 力所から上記葉位の小葉を 1 枚ずつ採取した. 採取後の小葉は速やかに電子天科で科量し生体重 (Fw) を求め, 水を充填した水槽に 2 時間浮かべて吸水 させた後, 葉の表面に付着した水分をテイッシュペー パーでふき取ってから再び科量し, 飽水時生体重 $\left(\mathrm{Fw}_{\max }\right)$ を求めた. その後, 小葉は乾燥機に入れ $70^{\circ} \mathrm{C}$ で 3 日間乾燥後, 秤量して乾物重 (Dw) を求めた。 RWC は, 以下の式によって算出した.

$$
\mathrm{RWC}(\%)=(\mathrm{Fw}-\mathrm{Dw}) /\left(\mathrm{Fw}_{\max }-\mathrm{Dw}\right) \times 100
$$

$\mathrm{Fw}$ : 生体重 $(\mathrm{mg}), \mathrm{Dw}$ : 乾物重 $(\mathrm{mg}), \mathrm{Fw}_{\max }$ : 飽水
時生体重 $(\mathrm{mg})$.

\section{結果}

\section{1. 培地内水分の減少にともなう相対茎径の推移と 菜身の光合成速度との関係}

\subsection{SD，MSD および RSD の推移}

給液停止後の培地内水分の滅少にともなう $\mathrm{SD}$, MSD 及び RSD の変化を Fig. 3 に示した. EC 2.0 区で は, 給液停止 1 日目の SD は直線的な増加を示し, MSD と SD はほとんど同じ值で推移した. RSDが 100\%以下となる時間帯はわずかであった。2 日目以降 では, SDの増加は鈍化する傾向がみられ, RSD が 100\%以下に低下する時間帯がしだいに増加した。特 に, 3 日目および 4 日目では, 12 時から 13 時に SD お よびRSD は急激に隇少するとともに，株全体の葉身 にしおれが観察された。そこで,この両日に $40 \mathrm{ml}$ の給 液を行った結果, 給液後 SD および RSD は増加し, 葉 身のしおれも回復した.なお,いずれの日も夜間の SD は概ね増加傾向を示したが, 一時的に減少する日も あった。 EC 6.0 区では, 給液停止 1 日目の SD は EC 2.0 区と同様に増加を示したが, EC 2.0 区に比べその 増加程度は小さかった. 2 日目以降の RSD は, 昼夜を 問わずしだいに 100\%以下となる時間帯が増加し, 日中 における RSD の最低值は隇少する傾向を示した. 特 に，4 日目における SD およびRSD は 9 時から 12 時
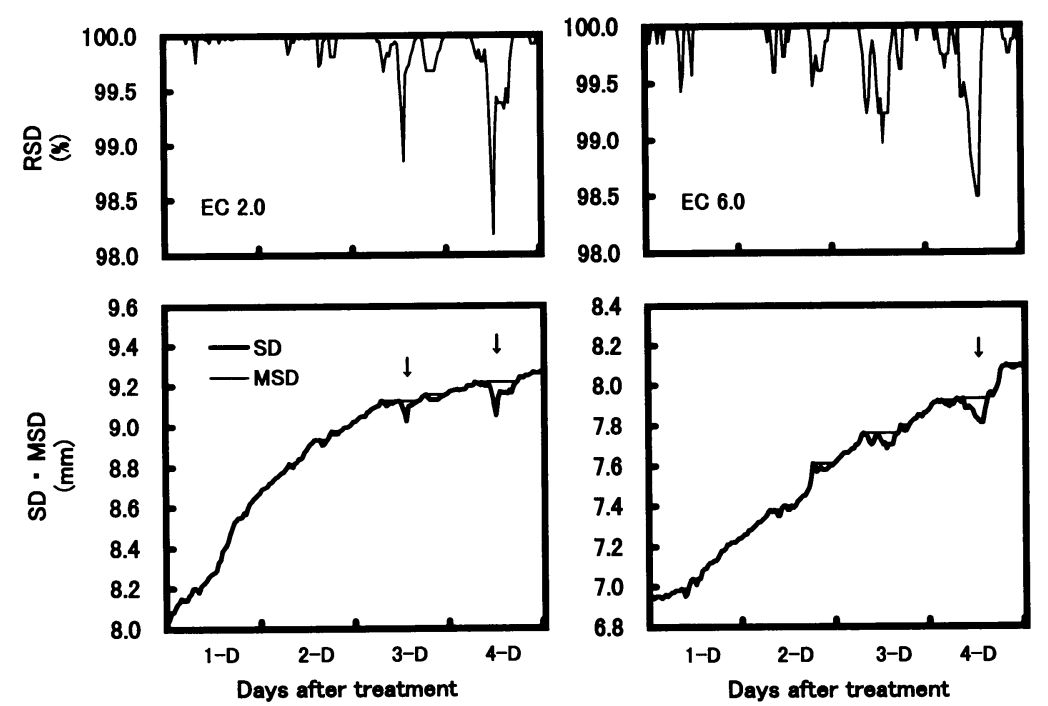

Fig. 3 Time courses of stem diameter (SD), maximum stem diameter (MSD) and relative stem diameter (RSD) during suspension of the nutrient solution supply at EC 2.0 and $6.0 \mathrm{dS} \cdot \mathrm{m}^{-1}$.

Arrows $(\downarrow)$ in the figure indicate the timing of irrigation. 

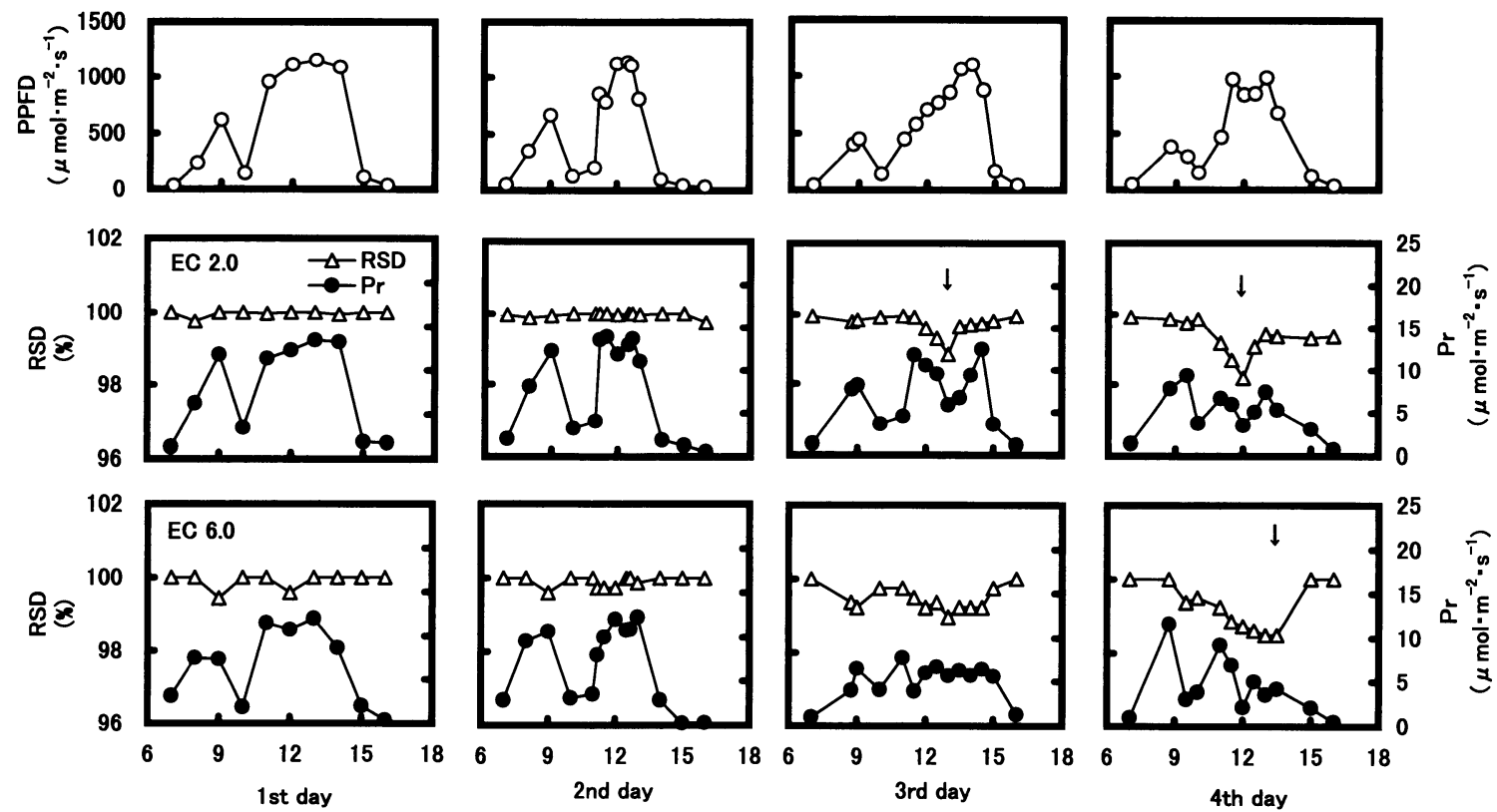

Time of day

Fig. 4 Time courses of relative stem diameter (RSD : $\triangle$ ), photosynthetic rate $(\operatorname{Pr}: \bigcirc)$ and photosynthetically photon flux density (PPFD: $\bigcirc$ ) during suspension of the nutrient solution supply at EC 2.0 and $6.0 \mathrm{dS} \cdot \mathrm{m}^{-1}$.

Arrows $(\downarrow)$ in the figure indicate the timing of irrigation.
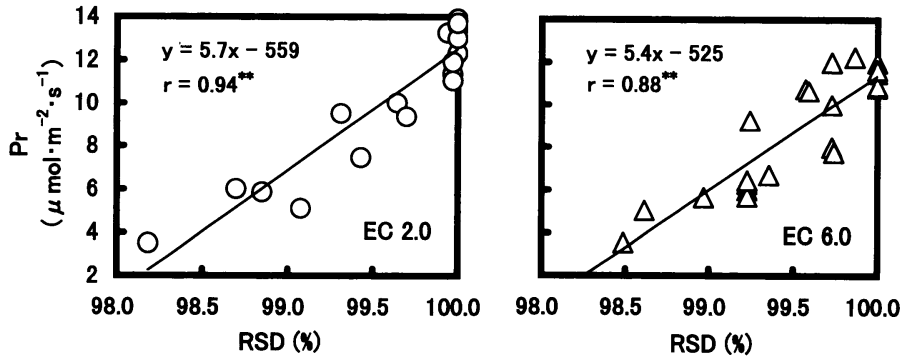

Fig. 5 Relationship between relative stem diameter (RSD) and photosynthetic rate (Pr) during suspension of the sutrient solution supply at EC 2.0 and $6.0 \mathrm{dS} \cdot \mathrm{m}^{-1}$.

These were measured at higher than $700 \mu \mathrm{mol} \cdot \mathrm{m}^{-2} \cdot \mathrm{s}^{-1}$ PPFD. ${ }^{* *}$, Significant difference at $p=0.01$.

に著しく減少し，株全体の葉身にしおれがみられたの で $40 \mathrm{ml}$ の給液を行った。その結果，SD および RSD は急激に増加し，しおれは回復した。なお，夜間の SD は増加傾向を示したが,一時的に減少する日もあった。

\subsection{RSD と菜身の $\operatorname{Pr}$ との閉係}

給液停止後の日中における RSD, 葉身のPr および Pr 測定時の PPFD の推移を Fig. 4 に示した。EC 2.0 区における給液停止 1 日目および 2 日目の RSD はほ ほ 100\%で推移し, Pr は PPFD の増加とともに上昇し, PPFD が減少すると低下した。 3 日目では, PPFD の増
加にともなって 12 時以降 RSD は急激に減少し, 同時 にPr も低下を示した。しかし, 給液後は RSD の増加 とともにPrも上昇した.また, 4 日目も RSD が隇少し た 11 時以降には，PPFDに関わらず Pr の上昇はみら れなかった，EC 6.0 区では，給液停止 1 日目及び 2 日 目の RSD は，PPFD の増加にともなってわずかに減 少した。また，Pr は PPFD が増加すると上昇し，隇少 すると低下する傾向がみられた。 3 日目の RSD は, PPFD の増加にともなって減少する傾向がみられ, Pr の上昇はみられなかった。また，4 日目の RSD は9 時 
から 13 時 30 分にかけて急激に低下し, Prも PPFD の 変化に関わらず低下傾向を示した。

培地内水分が充分ある給液停止 1 日目においては, $\operatorname{Pr} 4700 \mu \mathrm{mol} \cdot \mathrm{m}^{-2} \cdot \mathrm{s}^{-1}$ 以上の PPFDで飽和してい た。そこで, 光飽和点の $700 \mu \mathrm{mol} \cdot \mathrm{m}^{-2} \cdot \mathrm{s}^{-1}$ 以上におけ る Pr と RSD との関係を求めた結果, RSD と $\mathrm{Pr}$ との 間に EC 2.0 区では $r=0.94$, EC 6.0 区では $r=0.88$ の 有意な相関関係がみられた (Fig. 5).

2. 栽培条件における相対茎径と菜身の相対含水五 との閶係

\subsection{RSD および RWC の生育時期別日変化}

根域制限式養液栽培システムに生育したトマト株の
RSD，RWC およびPPFD の日変化を Fig. 6 に示し た. 9 月 10 日の測定では, PPFDの増加にともなって 葉身の RWC は 6 時以降隇少し, 8 時から 15 時までは ほほ一定値を示した後，16 時以降増加を示した。 RSD は, RWC と同様に 6 時から 9 時に隇少傾向を示し, そ の後日中はほとんど変化せず, PPFD が隇少する 14 時 から 18 時にかけて微增傾向がみられた. 10 月 6 日の 測定では, 9 月 10 日の測定と同様に PPFD の増加にと もなってRWC およびRSDは減少し, PPFDの減少に ともなって増加する日変化を示した。 11 月 7 日の測定 におけるPPFDは 9 月 10 日および 10 月 6 日の測定 に比べて小さかったが, RWC は 6 時以降 9 時まで減
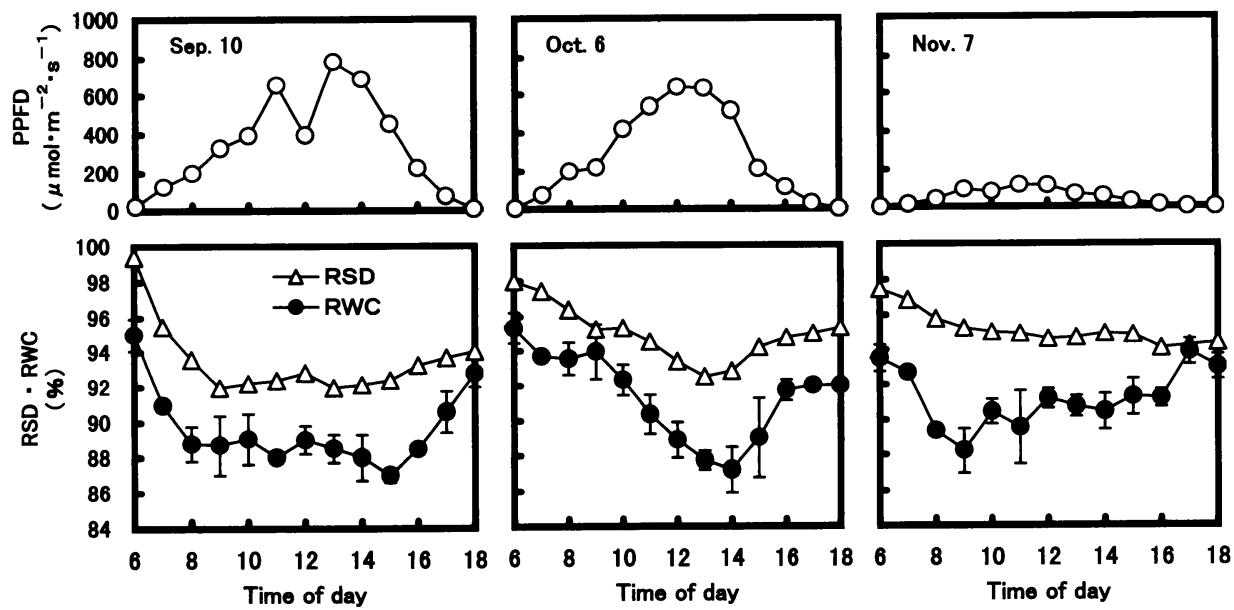

Fig. 6 Time courses of relative stem diameter (RSD : $\triangle$ ) and relative water content (RWC: $O$ ) in leaves of tomato plants cultivated with the hydroponics and photosynthetically photon flux density (PPFD: $)$ ) on Sep. 10, Oct. 6 and Nov. 7.

Maximum stem diameter (MSD) of these days were $11.7 \mathrm{~mm}, 12.4 \mathrm{~mm}$ and $13.0 \mathrm{~mm}$, respectively. Vertical bars indicate standard deviations in RWC.
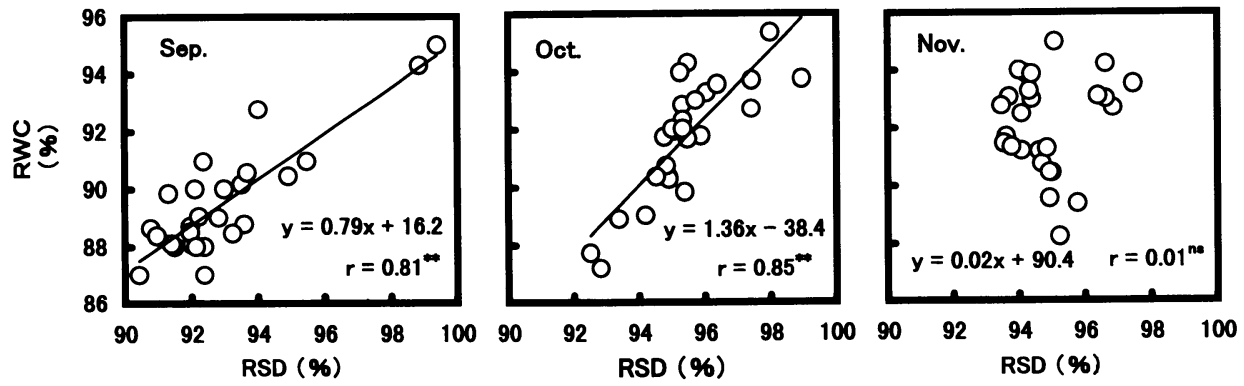

Fig. 7 Relationship between relative stem diameter (RSD) and relative water content (RWC) in leaves of tomato plants cultivated with the hydroponics on Sep. at flowering the first truss, Oct. at the end of flowering the second truss and Nov. at the start of harvesting the first truss.

**, Significant difference at $p=0.01$. ns, nonsignificant difference at $p=0.05$. 
少し, その後 18 時にかけて増加傾向を示した. これに 対し, RSD は 6 時から 18 時にわずかに減少しただけ だった。

\section{$2.2 \mathrm{RSD}$ と RWC との関係}

9 月, 10 月, 11 月測定における RSD と RWC との関 係を Fig. 7 に示した. 1 段花房開花期の 9 月測定及び 2 段花房開花終期の 10 月測定では, RSD と RWC との 間にそれぞれ $r=0.81, r=0.85$ の有意な相関関係がみ られた。これに対し，1 段花房収穫開始期の 11 月測定 では, RSD と RWC との間に相関関係はみられなかっ た $(r=0.01)$.

\section{考察}

本報告では, レーザ式変位センサを用いてトマト茎 径の連続測定を行った。従来の茎径測定法は, 茎に変 位センサを接触させるため, 測定器具が茎径変化に影 響を及ほすす可能性があり，長期間の測定には煩雑な調 整が必要であった（Nagano and Shimaji, 1976; Iwao and Takano, 1988a ; Imai et al., 1990).これに対し, 本測定法では茎径測定部位の上下位置を器具に固定す るだけで茎径の連続測定が可能であり, 測定中におけ る調整はほとんど必要ない。すずに本法は, トマト (Yamada and Kajioka, 1991 ; Nishina et al., 1998), 温 室メロン（Sato and Hasegawa, 1995）の茎径測定に用 いられている.

レーザ式変位センサによる茎径測定の結果, トマト のSD は生育過程を通じた水分変化と肥大生長とに よってダイナミックな日変化を示した. SD の変化か ら植物体の水分状態を評価するため Ishida (1985) は, 毎日の夜間の SD を結ぶ包絡線は水分ストレスがない 状態の SD とほほ等しいとし, 当日とその前日の午前 5 時の SD を結ぶ基準直線に対する SD の相対值(相対 茎直径)を指標として用いた(Ishida et al., 1989)。いつ 湾う, Sato and Hasegawa(1995) は, メロンの SD が 深夜から早朝にかけて直線的な増加を示すことから， 水分ストレスがない場合には日中でもその増加が継続 すると仮定し, 0 時から 5 時の SD の経時的変化から 求めた仮想直線に対する SD の相対值 (茎径膨縮率) を 指標として用いている. しかし, 今回の茎径測定の結 果から, 培地内水分が少ない条件では, 蒸散量の少な い夜間であっても SDに一時的な隇少がみられ (Fig. 3), 必ずしも直線的な増加を示さなかった。 また，そ の結果, 1 日の中で SD が最大となる時刻, 言い換える と水分ストレスが最も小さくなる時刻をあらかじめ特
定することは困難と思われた。これに関連して Iwao and Takano(1988b), Imai et al.(1990) は, 培地の乾 燥が進むと日中の SD の減少量に対する夜間の増加量 が小さくなることを指摘している．このことを考慮す ると, 本研究においてみられた夜間における SDの一 時的な減少は, 培地内水分が著しく減少し, 吸水や肥 大生長が抑制されることを通じて生じていると考えら れた(Ishida, 1985)。したがって，培地内水分が少ない 条件では, 特定の時間帯における SD の経時的変化を 基準として用いる Ishida et al.(1989), Sato and Hasegawa (1995) の指標は, 水分ストレスの評価に大きな誤 差を生じる可能性があり, 水分ストレスのない状態の $\mathrm{SD}$ の基準值の算出方法を改善する必要がある.

本研究では, SD の変化から茎の肥大生長にともな う最大茎径 (MSD) を随時求め, 日の出後の SD の減 少が体内水分の隇少によって生じると仮定し, SD の MSD に対する相対的変化によって水分ストレスを評 価しようとした。すなわち, RSD は特定の時間帯にお ける SD の経時的変化を基準としていないため, SD が パターン化できない複雑な経時的変化を示す場合で も, 安定的な水分ストレスの評価が可能である. RSD の特性を明らかにするため, 培地内水分の減少にとも なう葉身のしおれ状況との対応関係を観察するととも に, 葉身の生理的機能を表す指標の一つである Pr との 関係をみた。その結果，葉身にしおれが生じると同時 に RSD は著しい減少を示し, 両者に密接な対応関係 がみられた。また, Pr は培地内水分が充分ある条件で はPPFD と密接に関係して変化するが, 培地内水分が 隇少し葉身にしおれが生じるようになると, Pr は RSD と密接に関係して変化することが明らかとなっ た。このことは, 灌水制限によって水分ストレスが生 じたトマト葉身の光合成速度が気孔の閉鎖によって低 下したことを示している.また, Fusao and Iwao (1994) は, 土壤の乾燥と晴天とが重なった場合に限り, トマ 卜体内の水分ポテンシャルが低下し強い水分ストレス が発生することを明らかにした. 今回の結果でも, 培 地内水分の減少と PPFD の増加にともなう蒸散量の 増加とが重なることによって強い水分ストレスが生 じ, 葉身の光合成, 気孔の閉鎖などの生理的機能が著 しく低下したことを示唆した.これらのことから, 葉 身にしおれが生じる程度の水分ストレスが付与される 栽培条件では, RSDによって水分ストレスにともなう 葉身の生理的変化を評価することが可能であり, RSD は水分ストレスを評価するための指標として有効であ 
ると考えられた。なお，培責液 EC 濃度によって培地内 水分の減少にともなう SD の推移は大きく異なったが (Fig. 3), RSD と Pr との関係に著しい相違はみられな かった. したがって，RSDによって吸水抑制にともな う水分ストレスの影響を総合的に評価できる可能性が 示唆された。

RSD を指標にした給液制御を想定して, 根域制限式 養液栽培システムに生育した 1 株の RSD と同じ栽培 ベッドに生育した他株における葉身の RWC との関係 をみた結果,両者の間には 9 月および 10 月測定のいず れも密接な相関関係が認められた。これまで, 同一株 内における茎径変化と葉身の水分状態との関係は報告 されているが (Nagano and Simaji, 1976; Iwao and Takano, 1988b; Imai et al., 1990; Fusao and Iwao, 1994 ; Sato and Hasegawa, 1995), その他の株との関 係をみた報告は少ない. Nishina et al.(1998) は，本報 告と同様に等しい条件で生育した異なる株の茎径変化 と葉身の水ポテンシャルとの間に密接な関係があるこ とを報告している。このことは，畦の 1 株における RSD を追跡することによって, 等しい給液条件で管理 された個体群の水分ストレスを総合的に評価すること が可能であることを示している.しかし，1 段花房収穫 期の 11 月測定における RSD と RWC との関係は，9 月，10月測定のように密接な関係はみられなかった (Fig. 7)。これに関連して Nishina et al.(1998) は，卜 マトの茎径を部位別に同時測定した結果，茎の下部は 上部に比べ茎径変化が小さいことを報告している，す なわち，本報告では，いずれの生育ステージでも 2 節 と 3 節の間の茎径を測定したため, 加秢にともなって 茎の弾力性が失われ，葉身の水分変化に対する RSD の変化程度が小さくなった結果, RSD と RWC の間に 密接な関係が認められなくなったと推察された (Ishida, 1985)。このことから，トマトの長期栽培では 1 力所の茎径測定によって水分ストレスを評価するこ とには限界があり,さらなる検討が必要と考えられた。

以上のように, RSD を指標とすることによって, 水 分ストレスを非破壊で連続的に評価することが可能と 考えられた. 今後, RSD を指標にした給液制御システ ムの構築を図るとともに, 給夜及びトマトの収量, 品 質に及ほすす影響について検討を行う。

本研究の遂行にあたり中部電力 (株)の石田伸治氏, (株) 東芝の林 巧氏, 元同社の小山保徳氏には多大なご 協力をいただいた。また，本論文のとりまとめにあた
り, 東京農業大学の石原 邦教授, 静岡大学の棣谷 明 教授には貴重なご助言をいただいた。ここに記して深 く感謝の意を表します。

\section{文献}

Fusao, K., Iwao, K. 1994. Effect of soil moisture on diurnal variation of water content in tomato plant. (Japanese text with English title) Rep. Tokai Branch Soc. Agric. Meteorol. Jpn. (農気東海誌) 52 : 13-16.

Imai, S., Iwao, K., Fujiwara, T. 1990. Measurements of plant physiological information of vine tree and indexation of soil moisture control. (1) Analysis of stem diameter variation affected by environmental factors. (Japanese text with English abstract) Environ. Control in Biol. 28 : 103-108.

Imai, S., Honda, T., Fujiwara, T. 1994. Influence of soil moisture on daily variations of fruit and stem diameters of Japanese pear 'Kosui.' (Japanese text with English abstract) Environ. Control in Biol. 32 : 155-162.

Ishida, T. 1985. Water transport through soil-plant system. (Japanese text with English abstract) Bull. Yamagata Univ. Agric. Sci.(山形大学紀要(農学)) 9 (Extra Issue) : 616-621.

Ishida, T., Nagano, T., Higashiyama, I., Hunada, S. 1989. Automatic environment monitoring and regulating system for crop cultivation. - Development of automatic monitoring system-. (Japanese text with English abstract) Bull. Yamagata Univ. Agric. Sci.(山形大学紀要(農学))10: 839-847.

Iwao, K., Takano, T. 1988a. Studies on measurements of plant physiological informations and their agricultural applications. (1) Development of non-invasive measurements of water content in plant. (Japanese text with English abstract) Environ. Control in Biol. 26 : 139-145.

Iwao, K., Takano, T. 1988b. Studies on measurements of plant physiological informations and their agricultural applications. (2) Dynamics of water content in plants such as several crops and trees under natural conditions. (Japanese text with English abstract) Environ. Control in Biol. 26 : 163-170.

Kamota, F., Taniguchi, R., Kato, I., Sakata, K. 1972. Studies on the characteristic features of water consumption of various crops. VI. On the evapotranspiration of the indoor cultivation of vegetables. (Japanese text with English abstract) Bull. Tokai-Kinki Agric. Exp. Stn. (東近研報) 24 : 76-93.

Mitchell, J. P., Shennan, C., Grattan, S. R., May, D. M. 1991. Tomato fruit yields and quality under water deficit and salinity. J. Am. Soc. Hortic. Sci. $116: 215-221$.

Muramatu, Y. (村松安男) 1992. Cultivation of Tomato with High Quality and High Brix (高品質・高糖度のトマトつくり). (Japanese text) Nosan Gyoson Bunka Kyokai(農山漁村文化 協会), Tokyo, pp 10-19.

Nagano, T., Shimaji, H. 1976. Internal plant-water-status and its control. (1) Measurement of internal plant water status. (Japanese text with English abstract) J. Agric. Meteorol. 32 : 67-71.

Nakahara, M., Inoue, Y. 1997. Detecting water stress in differentially-irrigated tomato plants with infrared thermometry for cultivation of high-brix fruits. (Japanese text with English abstract) J. Agric. Meteorol. 53 : 191-199.

Nakamura, S., Horiuchi, M., Sano, H. 1988. Control of nutrient solution for "rockwool culture" of tomato. (Japanese text with English abstract) Bull. Shizuoka Agric. Exp. Stn. (静岡農試 
研報) 33 : 19-25.

Nishina, H., Yoshida, T., Nagatomo, K., Miyoshi, M., Hashimoto, Y. 1998. Production of tomato fruits with high brix in nutrient solution cultivation system with granular rockwool. (Part1) Measurement and analysis of physiological information of tomato plants under water stress. (Japanese text with English abstract) J. SHITA(植物工場学会誌) 10 : 113-118.

Oishi, N., Okatani, M., Koyama, Y. 1996. Development of hydroponics system for production of high soluble solids tomato by low node-order pinching and high density planting. (Japanese text with English abstract) Bull. Shizuoka Agric. Exp. Stn. (静岡農試研報) $41: 1-11$.

Sato, N. 1989. Automatic watering for the muskmelon accomplished by personal computer. (Japanese text with English abstract) Bull. Shizuoka Agric. Exp. Stn.(静岡農試研報) 34 : $1-21$.

Sato, N., Hasegawa, K. 1995. Prediction of relative water con- tent in muskmelon leaf from change in stem diameter by laser sensor. (Japanese text with English abstract) Bull. Shizuoka Agric. Exp. Stn. (静岡農試研報) 40:1-5.

Tanaka, K. 1987. New substrate and development of sensor in hydroponics. (固形培地新素材及びセンサの開発) (Japanese text) Agric. Hortic. (農業及び園芸) 62 : 111-118.

Tanaka, K., Yasui, H. 1992. Studies on practical application of rockwool culture for fruit vegetables. Bull. Natl. Res. Inst. Veg. Ornam. Plants Tea (野菜茶試研報) A5 : 1-36.

Tochigi, H., Kawasato, H. 1989. Effect of the soil moisture on the quality of tomato fruit in forcing culture (Japanese text with English abstract) Bull. Tochigi Agric. Exp. Stn. (栃木農試研 報) 36 : 15-24.

Yamada, H., Kajioka, R. 1991. Valuation of planting method by plant physiological measurements for petty-tomato cultivating in NFT. (Japanese text with English abstract) Environ. Control in Biol. 29 : 153-157. 